\title{
Immune response to respiratory syncytial virus in young Brazilian children
}

D.A.O. Q ueiróz',

E.L. Durigon ${ }^{2}$, V.F. Botosso ${ }^{3}$,

B. Ejzemberg ${ }^{4}$, S.E. Vieira ${ }^{4}$,

J.R. Mineo ${ }^{1}$, C. Yamashita ${ }^{4}$,

N. Hein ${ }^{4}$, C.L. Lopes ${ }^{4}$,

A.L. Cacharo ${ }^{4}$ and

K.E. Stewien²

\author{
${ }^{1}$ Departamento de Imunologia, Microbiologia e Parasitologia, \\ Instituto de Ciências Biomédicas, Universidade Federal de Uberlândia, \\ U berlândia, MG, Brasil \\ ¿2Laboratório de Virologia Clínica e Molecular, Departamento de Microbiologia, \\ Universidade de São Paulo, São Paulo, SP, Brasil \\ 3Serviço de Virologia, Instituto Butantan, São Paulo, SP, Brasil \\ ${ }^{4}$ Hospital Universitário, Universidade de São Paulo, São Paulo, SP, Brasil
}

\section{Correspondence \\ D.A.O. Queiróz \\ Departamento de Imunologia, \\ Microbiologia e Parasitologia \\ ICBIM, UFU \\ Av. Pará, 1720, Bloco 4C \\ 38400-902 Uberlândia, MG \\ Brasil \\ Fax: $+55-34-3218-2332$ \\ E-mail: dqueiroz@icbim.ufu.br \\ Some of these data were presented at the IX National Meeting of \\ Virology, São Lourenço, MG, Brazil, 1998. \\ Research supported in part by FAPESP (No. 7398/98). D.A.O. Queiróz was sponsored by CAPES (PICDT/UFG) and CNPq (No. 20108796-0) while obtaining her doctoral degree at the Departamento de Microbiologia, Universidade de São Paulo, São Paulo, SP, Brazil.}

Received March 29, 2001 Accepted July 11, 2002

\section{Abstract}

We have evaluated the cellular and humoral immune response to primary respiratory syncytial virus (RSV) infection in young infants. Serum specimens from 65 patients $\leq 12$ months of age ( 39 males and 26 females, 28 cases $<3$ months and 37 cases $\geq 3$ months; median $3 \pm$ 3.9 months) were tested for anti-RSV IgG and IgG subclass antibodies by EIA. Flow cytometry was used to characterize cell surface markers expressed on peripheral blood mononuclear cells (PBMC) from 29 RSV-infected children. There was a low rate of seroconversion in children $<3$ months of age, whose acute-phase PBMC were mostly $\mathrm{T}$ lymphocytes $(63.0 \pm 9.0 \%)$. In contrast, a higher rate of seroconversion was observed in children $>3$ months of age, with predominance of B lymphocytes (71.0 $\pm 17.7 \%)$. Stimulation of PBMC with RSV ( $2 \times$ $10^{5} \mathrm{TCID}_{50}$ ) for $48 \mathrm{~h}$ did not induce a detectable increase in intracellular cytokines and only a few showed a detectable increase in RSVspecific secreted cytokines. These data suggest that age is an important factor affecting the infants' ability to develop an immune response to RSV.

\section{Introduction}

Respiratory syncytial virus (RSV) is a leading cause of lower respiratory tract disease in infants and young children. The components of the immune response to RSV, which lead to protection or pathology, are not well understood, and this has hindered vaccine development $(1,2)$. There is a considerable amount of data about the humoral response to human RSV infection (3-5), but limited information about the cellular immune response (6-8). Studies on humans and

\section{Key words}

- Respiratory syncytial virus

- Peripheral blood

mononuclear cells

- Young children

- Surface antigens

- Cytokines animals have demonstrated that antibodies are important contributors to protective immunity (9-12) and that cellular immunity is important for clearing the infection $(13,14)$. The protective role of antibodies in human disease is probably best demonstrated by the correlation between higher levels of maternally acquired antibodies and less serious disease in infants $(9,10)$ and the ability of high titered RSV intravenous immunoglobulin (Ig) to decrease the risk of serious disease when administered prophylactically (15). The longer duration and severe complications of 
RSV infection in patients with reduced cellular immunity demonstrate the role of cellular immunity in clearing the infection $(16,17)$.

The peak age for hospitalization associated with RSV infection occurs in infants less than 6 months of age $(1,10)$, an age when maternally acquired antibodies are decreasing with a half life of about one month (18). The presence of these antibodies may not protect children against RSV infection $(19,20)$ and may even contribute to the disease process, as hypothesized by some investigators $(4,21)$. The poor antibody response to RSV infection in young infants may reflect in part the presence of maternally acquired antibodies. When an antibody response to RSV is detected it appears to be primarily of the IgG1 and IgG3 subclasses (22-24).

The type of cellular immune response is felt to be important in RSV infection. A Th1 type memory response (indicated by induction of IL-2 and/or IFN- $\gamma$ ) has been associated with live virus infection in animals and humans $(6,25,26)$ while a Th2 memory response (indicated by induction of IL-4, IL-5, and IL-13) has been associated with immunization with a formalin-inactivated RSV vaccine $(27,28)$. Some investigators have reported findings suggestive of a Th2 response $(7,29)$ in some patients during acute RSV infection.

To better understand the acute immune response to infection and pathogenesis of disease, we have characterized both the cellular and humoral responses to primary RSV infection in young infants. We determined the RSV-specific total and subclass IgG antibodies, surface markers on peripheral blood mononuclear cells (PBMC), and in vitro cytokine response to RSV stimulation of PBMC from acute- and convalescent-phase blood specimens from hospitalized RSV-infected children. Our data suggest that age is an important factor in both the infants' ability to induce an antibody response and the type of PBMC present in peripheral blood.

\section{Material and Methods}

\section{Patients}

From March 1995 to August 1996, the first two children $<15$ years of age, admitted each day to the University Hospital, USP, São Paulo, SP, Brazil, with acute fever with or without respiratory illness were enrolled in the study. Sixty-five of these children, who were $\leq 12$ months of age and whose parents gave informed consent to have peripheral blood and diagnostic specimens (nasopharyngeal aspirates - NPAs and swabs) collected, were included in the present study. The study was approved by the Ethics Committee of the University Hospital.

Most children (51/65) were admitted during the RSV season (April to July in São Paulo, SP, Brazil) and 40 were RSV-infected including 30 with lower respiratory tract illness (LRI), 4 with a mixed diagnosis of LRI and otitis media, 2 with otitis media, 2 with fever, and 2 with acute diarrhea. Of the remaining 25 patients, 16 had LRI including 5 with suspected RSV infection, 4 with adenovirus infection, 2 with parainfluenza 3 infection and 5 with no agent identified. Of the 9 patients without LRI, 6 had a diarrheal illness, 1 had varicella, 1 had urinary tract infection, and 1 had sepsis. The clinical specimens were collected 1-4 days after admission from all patients (most of them on the second day - 93\%), and convalescent blood specimens were collected 1-15 months later. From 19 RSV-infected patients we obtained two or three convalescent serum specimens.

We looked for the presence of RSVspecific antibodies in all 65 patients, but we were able to detect an antibody response to infection only in 37 of 40 RSV-infected children. We focused our analysis on surface markers of 40 PBMC specimens collected from 29 RSV-infected patients. Four patients had acute-phase PBMC only, 11 had both acute- and convalescent-phase PBMC, and 14 had only convalescent-phase PBMC 
available for study. The PBMC specimens were grouped according to patient age and to the acute or convalescent phase of illness.

\section{Specimens}

NPAs were collected from one nostril after instillation of $0.5 \mathrm{ml}$ phosphatebuffered saline (PBS, pH 7.2) and the other nostril was swabbed. The swab and NPA specimens were placed on ice and transported immediately to the laboratory, where they were mixed and divided into two aliquots, one for tissue culture isolation studies and the other for immunofluorescent assay (IFA) testing for respiratory viruses.

PBMC were separated from heparinized blood by sedimentation using lymphocyte separation medium (Organon Tecnika Corporation, Durham, NC, USA) according to manufacturer directions. Washed PBMC were stored in $85 \%$ fetal bovine serum (FBS, Gibco Laboratories, Grand Island, NY, USA) and 15\% glycerol (Boehringer Mannheim Corp., Indianapolis, IN, USA) at $-70^{\circ} \mathrm{C}$. Later the vials were stored in liquid nitrogen. Control PBMC were obtained from 3 adult donors, isolated as described above, washed, pooled and frozen at $-70^{\circ} \mathrm{C}$ in $90 \%$ FBS plus $10 \%$ DMSO (Sigma, St. Louis, MO, USA).

\section{IFA for respiratory virus antigens}

The combined NPA and swab specimens were washed twice with PBS and the pellet was resuspended in PBS and pipetted onto multispot slides, dried at room temperature, fixed with acetone, and stored at $-20^{\circ} \mathrm{C}$ until the time for use. The specimens were reacted against a panel of antirespiratory virus monoclonal antibodies (Respiratory Virus Panel I: Viral Screening and Identification kit, Chemicon International Inc., Temecula, CA, USA, kindly provided by Dr. David Beckman) according to manufacturer instructions. Although the kit is well standardized for cell culture, its application directly to NPA gave higher than expected background. Thus, a specimen was considered positive for RSV if $>3$ cells gave RSV-specific fluorescence, negative if no virus-specific fluorescence was observed and $\geq 20$ epithelial cells were visualized, inconclusive if $<20$ epithelial cells were visualized, and suspected if 1-3 cells gave RSV-specific fluorescence.

\section{Virus isolation}

An NPA and swab mixture $(0.15 \mathrm{ml})$ was placed on 2 or more sub-confluent HEp-2, NCI-H292 (ATCC CCL-23, CRL-1848, respectively) or HeLa-I (30) cell monolayers grown in 24-well polystyrene microplates (Corning Inc., New York, NY, USA). If no cytopathic effect was detected, the cells were blind passaged twice. Cells showing a cytopathic effect were tested by IFA for the respiratory virus antigens noted above.

\section{RSV-specific antibody assays}

An indirect enzyme immunoassay (EIA) described by Carpenter (31) was used to detect RSV-specific total IgG, IgG1, IgG2, IgG3, and IgG4 antibodies. Briefly, the serum specimen was diluted 1:100 in PBS and reacted against RSV-infected and-uninfected tissue culture cell lysate antigen (diluted 1:20 in PBS) adsorbed to wells of Immulon II microtiter plates (Dynatech Laboratories Inc., Chantilly, VA, USA). Antibodies specific for human IgG or IgG subclasses reacting against the RSV antigens were detected with biotinylated monoclonal antibodies (Hybridoma Reagent Laboratory, Baltimore, MD, USA) and peroxidase-conjugated streptavidin (Amersham International, Amersham, UK). A serum specimen was considered to be positive if $[\mathrm{P}-\mathrm{N}]$ (the mean of the duplicate values for the RSV-infected wells [P] minus the mean of the duplicate values for RSV-uninfected wells [N]) was $>9$ standard deviations (SD) above the mean of the negative control serum specimens. A specimen 
was considered to be negative if its [P - N] was less than $6 \mathrm{SD}$ above the mean of the negative control serum specimens. The positive results (acute to convalescent pairs) were titrated (1:100 to 1:12800) in order to define a significant rise from acute to convalescent specimens. A significant rise (seroconversion) in specific antibodies to RSV was defined as a $\geq 50 \%$ increase in absorbance value for children $>3$ months of age (which approximates a 4-fold rise in antibody titer). The magnitude of the antibody response, as indicated by absorbance reading, was substantially lower in the $<1-3$-month-old children compared to the older children. Since seroconversion could be masked by the simultaneous decay in maternally acquired antibody, we compensated for the decay in maternal antibody by adjusting for its expected $\sim 1$ month half-life by considering a 2fold rise for convalescent-phase specimens collected $<2$ months later to be indicative of RSV infection, and no fall in antibody for convalescent-phase specimens collected $>2$ months later to be indicative of infection.

\section{RSV stimulation of PBMC}

PBMC were thawed and transferred to a $50-\mathrm{ml}$ conical tube containing $40 \mathrm{ml}$ of TCM (S-MEM, supplemented with 5\% heat-inactivated human $\mathrm{AB}^{+}$serum plus $1 \%$ essential amino acids, $1 \%$ non-essential amino acids, $1 \%$ sodium pyruvate and L-glutamine, all from Gibco), incubated at $37^{\circ} \mathrm{C}$ for $10 \mathrm{~h}$, washed twice in PBS, and resuspended to 6 $\mathrm{ml}$ in TCM. An amount of 0.3-1 x $10^{6}$ viable cells/ml (counted by Trypan blue exclusion) was added to 24-well microplates (Costar Corporation, Cambridge, MA, USA) and stimulated with phytohemagglutinin (PHA, $10 \mu \mathrm{g} / \mathrm{ml})$, the RSVA2 (Long strain) $\left(2 \times 10^{5}\right.$ $\left.\mathrm{TCID}_{50}\right)$, the RSV B $(18537)\left(2 \times 10^{5} \mathrm{TCID}_{50}\right)$ and the control uninfected HEp-2 cell lysate as described (6). After incubation at $37^{\circ} \mathrm{C}$ for $48 \mathrm{~h}$ the cells were harvested for flow cytometry studies and the supernatant was col- lected and frozen at $-70^{\circ} \mathrm{C}$ for the determination of secreted cytokines.

\section{Detection of surface antigens and intracellular cytokines}

Flow cytometry was performed using a modified 96-well microplate assay (described by Pharmingen, San Diego, CA, USA). Briefly, PBMC were reacted against fluorescence-labeled anti-human CD3 (SK7), CD4/ CD8 (SK3/SK1), CD20 (L27), isotypes as negative controls (Becton Dickinson Company, San Jose, CA, USA), IgM (G20-127), HLA class I (G46-2.6), class II (TU39) and anti-IL-2 (MQ1-17H12), -IL-4 (MP4-25D2), -IL-5 (TRFK5) and -IFN- $\gamma$ (4S.B3) (Pharmingen) antibodies. For intracellular cytokine analysis, $\mathrm{PBMC}$ were cultured with Brefeldin A $(10 \mu \mathrm{g} / \mathrm{ml}$; Sigma) for $2 \mathrm{~h}$, reacted against FITC-labeled anti-CD3 antibody, fixed with $4 \%$ paraformaldehyde (Ted Pella, Inc., Redding, CA, USA), permeabilized with PBS containing $0.1 \%$ saponin (Sigma), and stained with PE-labeled anti-IL-2, -IL-4, -IL-5 and -IFN- $\gamma$ antibodies. The cells were analyzed with a FACScan apparatus (Becton Dickinson Immunocytometry Systems) using the CellQUEST software from the same company.

An intracellular cytokine test was considered positive if the ratio between the percentages of RSV, PHA and negative control (supernatant of lysate of uninfected HEp-2 cells) stimulus was $\geq 2$.

\section{FlowMetrix analysis of secreted cytokines}

A multiplex assay was used to detect cytokines (IL-2, IL-4, IL-5, and IFN- $\gamma$ ) in the supernatant of stimulated PBMC. Briefly, anti-human IL-2 (MQ1-17H12), -IL-4 (8D48), -IL-5 (TRFK5), and -IFN- $\gamma$ (NIB42)(Pharmingen) capture monoclonal antibodies were covalently coupled (32) to latex beads (Luminex Corp., Austin, TX, USA). The beads were reacted against $100 \mu 1$ of experimental 
or control samples and the captured cytokine was detected with the corresponding biotinylated detector monoclonal antibody, followed by streptavidin-FITC (Alexa, Molecular Probes, Eugene, OR, USA). FACScan and FlowMetrix computer systems and the Luminex software were used to detect beads.

The sensitivities of the assays for secreted cytokines were $8 \mathrm{pg} / \mathrm{ml}$ for IL-2, $4 \mathrm{pg} /$ $\mathrm{ml}$ for IL-4, $6 \mathrm{pg} / \mathrm{ml}$ for IL-5 and $17 \mathrm{pg} / \mathrm{ml}$ for IFN- $\gamma$ (defined using human recombinant cytokines).

\section{Statistical analysis}

We used the Graphpad Prism, version 2.01, 1998 software and Statistica for Windows, version 4.5, 1993. To compare surface markers of PBMC from unpaired groups of patients we used nonparametric tests. The Kruskal-Wallis test was used when three or more simultaneous groups were compared and the Mann-Whitney test when two groups were compared. To analyze the differences in percentages according to gender and age we used binomial distribution. In all cases, differences were considered significant when $\mathrm{P}<0.01$.

\section{Results}

\section{Prevalence of RSV-specific antibodies}

In order to determine the presence of RSV-specific antibodies in infants we tested the acute-phase serum specimens by EIA. The data were grouped according to the presence of RSV infection and according to infant age (Table 1). The most commonly detected IgG subclass was IgG1, with only 3/65 patients showing IgG3 and none showing detectable IgG2 or IgG4 antibodies. As expected, RSV-specific maternally acquired IgG antibodies (total IgG) were present in all children $<1-3$ months of age and then rapidly decreased in prevalence in 3-6- and 6-9month-old children, consistent with the expected decay in maternal antibody. They then increased in the 9-12-month-old children, consistent with the expected high rate of RSV infection during the first year of life. IgG titers, as indicated by absorbance reading, followed a pattern similar to that of antibody prevalence, i.e., median absorbance decreased in the 6-9-month-age group and increased in the 9-12-month-age group (Figure 1).

\begin{tabular}{|c|c|c|c|c|c|c|c|c|}
\hline $\begin{array}{l}\text { Age } \\
\text { (months) }\end{array}$ & $\begin{array}{c}\mathrm{RSV}^{+1} \\
\mathrm{~N} \text { (median) }\end{array}$ & $\begin{array}{c}\text { Total IgG } \\
\mathrm{N}(\%)\end{array}$ & $\begin{array}{l}\text { IgG1 } \\
\mathrm{N}(\%)\end{array}$ & $\begin{array}{l}\text { IgG3 } \\
\text { N (\%) }\end{array}$ & $\begin{array}{l}\text { Other cases² } \\
\mathrm{N} \text { (median) }\end{array}$ & $\begin{array}{c}\text { Total IgG } \\
\mathrm{N}(\%)\end{array}$ & $\begin{array}{l}\text { IgGI } \\
\mathrm{N}(\%)\end{array}$ & $\begin{array}{l}\text { IgG3 } \\
\text { N (\%) }\end{array}$ \\
\hline$<1-3$ & $21(1.0 \pm 0.5)$ & $21(100.0)$ & $17(81.0)$ & 0 & $7(1.0 \pm 0.7)$ & $7(100.0)$ & 7 (100.0) & $1(14.3)$ \\
\hline $3-6$ & $10(4.5 \pm 1.0)$ & $5(50.0)$ & $4(40.0)$ & 0 & $7(5.0 \pm 0.8)$ & $6(85.7)$ & 2 (33.3) & 1 (16.7) \\
\hline $6-9$ & $2(7.0 \pm 1.4)$ & $1(50.0)$ & 0 & 0 & $4(7.0 \pm 0.8)$ & 0 & 0 & 0 \\
\hline $9-12$ & $7(12.0 \pm 1.3)$ & $3(42.9)$ & $3(42.9)$ & 0 & $7(12.0 \pm 1.5)$ & $5(71.4)$ & $3(42.8)$ & $1(14.3)$ \\
\hline Total & $40(2.0 \pm 3.9)$ & $30(75.0)$ & $24(60.0)$ & 0 & $25(5.0 \pm 3.9)$ & $18(72.0)$ & $12(48.0)$ & $3(12.0)$ \\
\hline
\end{tabular}

${ }^{1} \mathrm{~N}$ - number of RSV-positive cases; the median age in months ( \pm SD) is given in parentheses. ${ }^{2}$ Of the 25 patients, 5 had suspected RSV infection by immunofluorescence. IgG2 and IgG4 isotypes were not detected in any of the 65 patients. 


\section{Antibody response to RSV infection}

When we tested acute and convalescent specimens from each age group we detected a high rate (12/17) of seroconversion in children $>3$ months of age and a lower rate $(1 / 20)$ in younger children. When an approximate 2-fold rise or lack of decrease was considered, only 4 of 20 children $<1-3$ months showed an antibody response to RSV infection (Figure 2). The IgG1 profile was similar to that of total $\operatorname{IgG}$, but with lower levels. IgG3 was detected in 8/17 patients who were

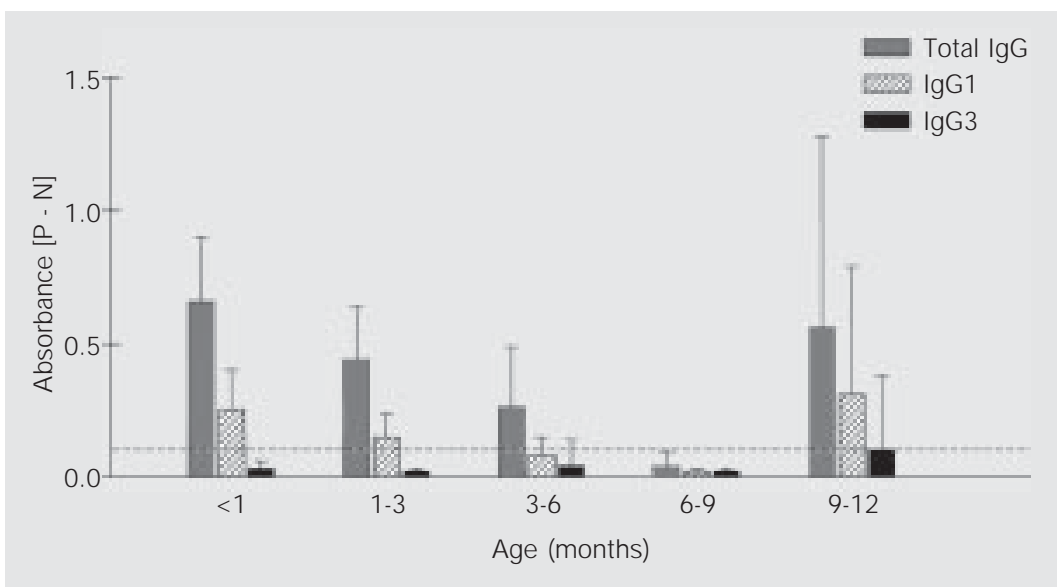

Figure 1. Respiratory syncytial virus (RSV)-specific total IgG, IgG1 and IgG3 antibody levels by age in serum specimens from children admitted with acute fever due to RSV infection $(\mathrm{N}=40)$ or other etiologies $(\mathrm{N}=25)$. IgG2 and IgG4 isotypes were not detected. Ordinate, $[\mathrm{P}-\mathrm{N}]$ : the mean of duplicate values for the RSV-infected wells $[\mathrm{P}]$ minus the mean of the duplicate values for RSV-uninfected wells [N]. The dashed line shows the cut-off value (0.1). infected with RSV at age $\geq 3$ months (data not shown).

The additional convalescent-phase serum specimens obtained from 19 RSV-infected children demonstrated that at 3-4 months after infection the titers began to decrease, as indicated by absorbance reading. We also noted serological evidence of a second RSV infection in 2 children, both of whom had their first infection at $<3$ months of age (data not shown).

\section{T and B lymphocyte surface markers}

On the basis of age and timing of specimen collection relative to the infection, i.e., acute or convalescent phase, we assigned the specimens to five groups (Table 2). We also tested the collected PBMC to investigate the $\mathrm{T}$ and $\mathrm{B}$ cell populations by flow cytometry (Figure 3$)$. The frequency of $\mathrm{T}$ cells $\left(\mathrm{CD}^{+}\right.$ and $\mathrm{CD}^{+}$) and HLA class I were significantly higher in the young infants of group 1 when compared with the older infants of group $2(\mathrm{P}<0.01)$. Conversely, the frequency of B lymphocytes $\left(\mathrm{CD} 20^{+}\right.$and $\left.\mathrm{IgM}^{+}\right)$as well as HLA class II was significantly higher in group 2 when compared with group 1 $(\mathrm{P}<0.01)$. For the remaining groups, except the 12-23 months of age (convalescent-phase specimens), B lymphocytes predominated over $\mathrm{T}$ cells, but the differences were not significant. Comparison of all five groups
Figure 2. Respiratory syncytial virus (RSV)-specific total IgG antibodies in 37 pairs of sera collected from RSV-infected patients. Ordinate, $[\mathrm{P}-\mathrm{N}]$ : the mean of the duplicate values for the RSV-infected wells $[P]$ minus the mean of the duplicate values for RSV-uninfected wells [N]. The solid lines indicate a significant rise from acute to convalescent specimens; the dashed lines indicate a decrease or a nonsignificant rise from acute to convalescent specimens. These graphs were constructed using an assay with serum specimens diluted 1:100. Conv, convalescence.
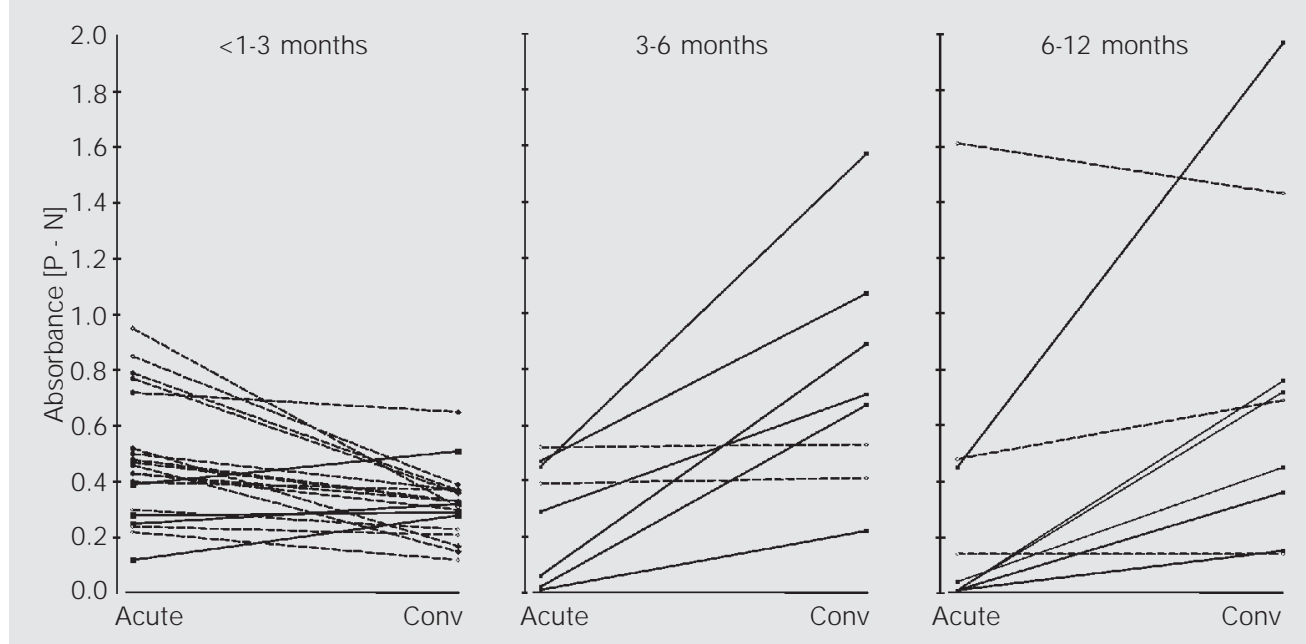
showed significant differences among them for most of the surface markers analyzed, i.e., CD3, CD4, CD20, HLA class I and class II $(\mathrm{P}<0.01)$. Regarding the $\mathrm{CD} 4 / \mathrm{CD} 8$ ratio, there was an apparent difference between groups 1 and 2 which, however, was not significant $(\mathrm{P}=0.028)$. There was a slight inversion in phenotype from the acute to the convalescent samples for 11 patients who had acute and convalescent specimens analyzed (data not shown), for whom the median sample collection interval between acute and convalescent specimens was approximately 2 months.

\section{Intracellular and secreted cytokines}

The 40 PBMC specimens subjected to in vitro stimulation showed little RSV-specific increases (ratio of percent intracellular cytokines for RSV stimulation/control stimulation $>2$ ) in intracellular or secreted cytokines (data not shown). Among the 15 acute-phase specimens (groups 1 and 2), 6 had an RSVspecific increase in intracellular cytokine expression, but for only one cytokine. Four of the 6 increases were for Th1 (IL-2 or IFN$\gamma$ ) and 2 were for Th2 (IL-4 and IL-5) cytokines. Among the 21 convalescent-phase specimens, 14 showed an RSV-specific increase for one cytokine ( 9 specimens) or for two cytokines (5 specimens). Eight of the 19 increases were for Th1 (IL-2 or IFN- $\gamma$ ) cytokines and 11 were for Th2 (IL4 and IL-5) cytokines.

The average increase (in 16 experiments) of RSV-specific intracellular and secreted cytokines was slightly higher for IL-2 cytokines in control PBMC when compared to RSV-specific stimulation of IL-4, IL-5 and IFN $-\gamma$. On the other hand, when control PBMC were stimulated with PHA they expressed high levels of intracellular cytokines (Figure 4) and the values obtained for secreted cytokines were 6,453 pg for IL-2, $5,439 \mathrm{pg}$ for IFN- $\gamma, 77.3 \mathrm{pg}$ for IL-4 and 256 pg for IL-5.

Table 2. Group distribution of 40 PBMC specimens obtained from 29 children during the acute phase of respiratory syncytial virus infection and/or during convalescence tested for surface receptors.

\begin{tabular}{crccc}
\hline Groups & $\mathrm{N}^{1}$ & Age (months) & Median age \pm SD & Phase \\
\hline 1 & 10 & $<1-3$ & $1.0 \pm 0.4$ & Acute \\
2 & 5 & $3-6$ & $4.0 \pm 1.0$ & Acute \\
3 & 10 & $3-6$ & $4.0 \pm 0.7$ & Conv \\
4 & 5 & $6-9$ & $7.0 \pm 1.0$ & Conv \\
5 & 10 & $12-23$ & $15.5 \pm 4.2$ & Conv \\
\hline
\end{tabular}

${ }^{1}$ Number of specimens analyzed (PBMC were collected from 11 infants during the acute phase of the disease and during convalescence). Conv, convalescence.
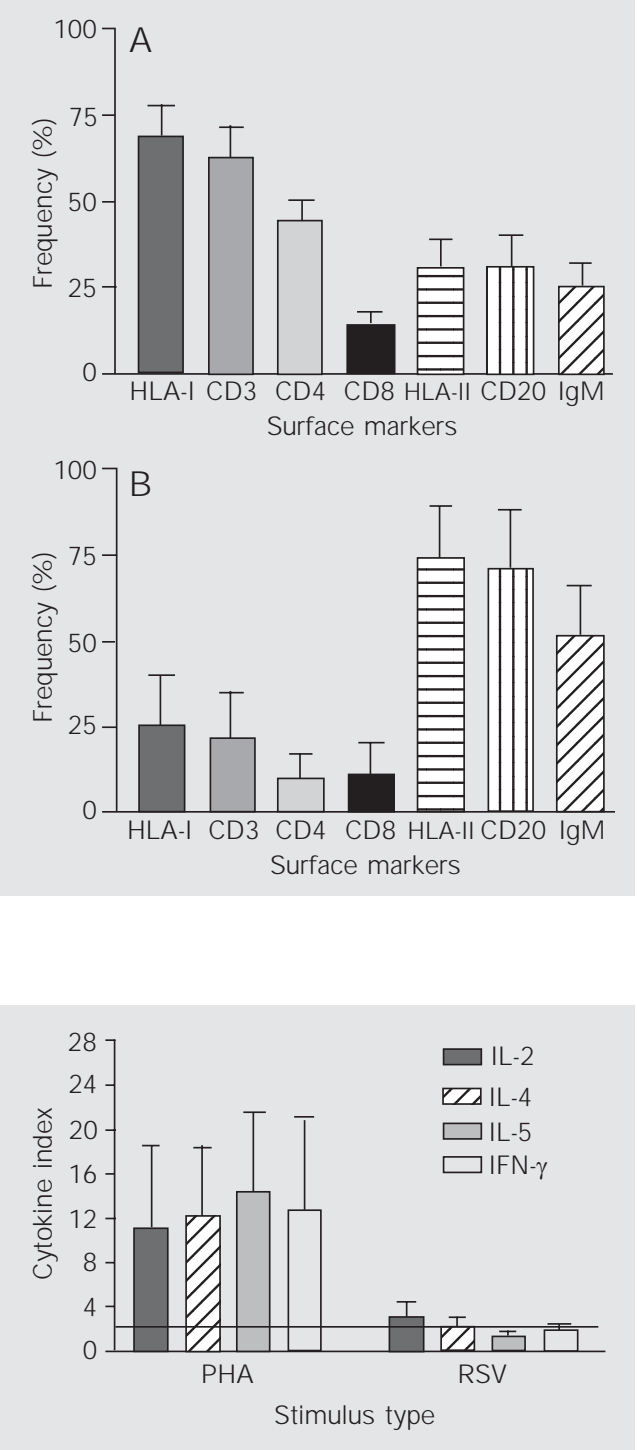

Figure 3. Frequency of $\mathrm{T}$ and $\mathrm{B}$ lymphocyte surface markers in acute respiratory syncytial virus PBMC population specimens from 10 children, one month of median age (A), and from 5 children, four months of median age (B).
Figure 4. Detection of intracelIular cytokines expressed in PBMC of blood donors (control PBMC) during 16 different experiments after in vitro stimulation with respiratory syncytial virus (RSV) and the mitogen phytohemagglutinin (PHA). The horizontal line represents the cut-off value (2.0). Data are reported as median \pm SD. 


\section{Discussion}

The decrease in RSV-specific antibodies detected in infants $<1$ month to 6 months of age is consistent with the loss of maternal antibodies, as reported previously $(5,18)$. In the present study, examination of sera from RSV-infected children revealed that the total IgG levels were higher than IgG1 levels. A possible explanation is that we used an indirect EIA method, which may not have detected small amounts of other IgG subclasses. Alternatively, since IgG3 has a half-life of 8 days in vivo (33) and was detected in only $1 / 28$ acute cases $<3$ months, it is possible that maternal $\operatorname{IgG} 3$ antibodies had already decreased. It is also possible that IgG3 was not transmitted or was transmitted in amounts too small to be detected. Wilczynski and Lukasik (34) reported that RSV-specific IgG3 antibodies are more frequent in mothers than in their offspring. More recently, another study suggested that RSV-specific IgG1 is the favored subclass transferred to the offspring (35). Another finding was that RSV acute infection was higher $(\mathrm{P}<0.01)$ in males than in females (data not shown), as also reported by others $(9,36)$.

The present results, which indicate that IgG1 and IgG3 subclasses predominate after primary RSV infection, agree with those of other investigations $(3,22,24)$. The small number of seroconversion cases observed for infants that were infected before 3 months of age also agrees with others and suggests that the humoral immune response is weak in young infants $(19,24,37)$. Tsutsumi et al. (38) did not detect RSV-specific IgG seroconversion in nasopharyngeal secretions of children $<2$ months of age and observed that the titer of RSV-specific IgG was significantly lower in children $<8$ months than in children 8-17 months. Brandenburg et al. (18) showed that only $7 / 32$ RSV-infected children $<6$ months of age produced significantly increased neutralizing antibodies. The lower magnitude of the humoral immune response to RSV in children $<3$ months may suggest that: i) maternal antibodies may interfere with IgG-producing cells and mediate a temporary immunosuppression in infants; ii) most of the children $<3$ months are not able to produce sufficiently high antibody titers to be protected; iii) in most cases maternal antibodies did not have enough neutralizing activity against the RSV strains which caused the infections. Brandenburg et al. (18) found variable titers of neutralizing antibodies (33 to 1382) in infants at birth, a fact that could explain, at least in part, why some children produce RSV-specific antibodies and others do not.

Our inability to detect IgG3 in some of the older convalescent specimens examined may be related to the relatively long intervals between serum collections (2-5 months). Hornsleth et al. (22) showed that the peak production of IgG3 is approximately 3 weeks, and that it subsequently decreases during the following months. In the same study, it was demonstrated that IgG1 peaks approximately 4 weeks following infection and persists for several months. Jankowski et al. (23) observed that IgG1 increased, whereas IgG3 decreased, in the late convalescent phase. Although total $\operatorname{IgG}$ antibody responses to RSV were detected in most of the infants $>3$ months, we observed that the antibody tended to decrease at 3-4 months post-infection. We did not detect either IgG2 or IgG4 RSVspecific antibodies in the serum specimens examined, in contrast to observations made by Rabatic et al. (7) who detected IgG4 in 6/10 RSV-infected patients. The production of IgG1 and IgG3 is important for immunity, since these subclasses are most active in complement fixation and antibody-dependent cell-mediated cytotoxicity reactions (33).

As expected, the results concerning HLA class I and class II were correlated with $\mathrm{T}$ cell markers (CD3) and B lymphocyte markers (IgM and CD20), respectively. The significant difference in surface markers (CD3, CD4, CD20, IgM and HLA class I and class 
II) observed between groups 1 and 2 could reflect the presence of higher maternal antibody titers in the younger, acutely ill infants ( $<1-3$ months). Raes et al. (8) detected an increased number of $\mathrm{CD}^{+}$cells $(\mathrm{P}<0.01)$ in RSV-infected children $<4$ months when compared with children $>4$ months. However, since we had no control specimens for group 1 , we were not able to determine if the proportions of $\mathrm{T}$ and $\mathrm{B}$ cells were altered by the infection. In addition, the proportion of $\mathrm{T}$ lymphocytes in these specimens was similar to that previously reported (39) as the normal range for the age. The increased number of B lymphocytes, especially of $\mathrm{CD} 20^{+}$cells in the older acutely ill infants (3-6 months), suggests that B cells were activated. A similar study also found an increased number of B lymphocytes in RSVinfected infants with median age close to that of the older group of the present study $(7,8,29)$. Brandenburg et al. (18) proposed that the limitation of the serological methods in detecting RSV infection in children under 6 months of age could be due, at least in part, to the relative inability of young infants to initiate a specific antibody response to the infection. Durandy et al. (40) have shown that relatively few mature $B$ cells exist in the peripheral blood of human neonates, and proposed that lower levels of CD40 in the membranes of B cells, together with the lack of CD40 ligands on $\mathrm{T}$ lymphocytes, may account for the low production of IgG early in life. The $\mathrm{CD}^{+} / \mathrm{CD}^{+}$ratio for the youngest group in our study was similar to the normal ratios reported by Comans-Bitter et al. (39). However, for children of group 2, whose percentage of $\mathrm{CD}^{+} / \mathrm{CD}^{+}$cells was about the same for 4 of 5 infants, the ratio was lower. The other patient of the second acute group, who had higher ratio of $\mathrm{CD}^{+} /$ $\mathrm{CD}^{+} \mathrm{T}$ cells, was admitted to the intensive care unit.

The differences in surface markers (CD3, CD4, IgM, CD20, HLA class I and class II) observed among groups 1 to 5 probably re- flects group heterogeneity concerning age and, principally, timing of PBMC collection (acute $v s$ convalescent). Since the interval of sample collection was relatively long, differences in surface markers observed for convalescent cases (groups 3, 4 and 5) could not be correlated with RSV infection.

The relative numbers of $T$ cells detected here for control PBMC (data not shown) were similar to those observed by McCloskey et al. (41) for the normal adult range, while the values of B lymphocytes were similar to those reported by Hamilton (33).

The results revealed that intracellular and secreted cytokine expression depended on cell number during stimulation. However, cytokine expression was also dependent on cell phenotype. As expected, T cell cytokines were expressed less when B lymphocytes predominated over T cells. In our study, RSV-specific stimulation of PBMC could induce some specific cytokines, although it was not possible to define any pattern. In contrast, Brandenburg et al. (26) observed a type 1-like immune response when stimulating $\mathrm{T}$ cell cultures established from PBMC of children with RSV infection. We found that most PBMC responded to a polyclonal stimulus with PHA and producing either Th1 or Th2 cytokines. Since the majority of cells expressed cytokines during PHA stimulation, and not during RSV stimulation, it is possible that: i) RSV stimulation was not optimal; ii) RSV does not induce detectable levels of memory lymphocytes after primary infection or the half-life of these cells is so short that this percentage declines rapidly; iii) RSV infection of children's PBMC was immunosuppressive. The potential for immunosuppression is indicated by the finding that exposure of human PBMC to RSV induced both IL-1 inhibitory activity and suppression of ICAM-1/LFA-1 expression. Thus, altered ICAM-1/LFA-1 expression failed to elicit the early events necessary for cellular collaboration, contributing to early suppression of the clonal expansion of RSV- 
specific lymphocytes (42).

To better understand the importance of $\mathrm{RSV}$-specific maternal or natural antibodies and disease, it would be helpful to conduct a case-control study in neonates, comparing at least four categories of age: infants $<3$ months of age, 3-6 months, 6-9 months and 9-12 months. In addition, our understanding of RSV-specific cytokines would benefit from investigation of PBMC from acute-phase and 1-month convalescent-phase patients in order to evaluate the development of memory cells.

The difference in the infant's ability to initiate an antibody response during the acutephase of RSV infection between young and older infants is probably due to immaturity of the young infant's immune system or to the presence of maternal antibodies. The present data suggest that both the antibody and cell immune response to RSV are dependent, in part, on the age of the infected patient.

\section{Acknowledgments}

We thank Drs. Larry J. Anderson, Ralph A. Tripp, Dean D. Erdman and Cecilia J. Tsou, Respiratory and Enteroviruses Branch, Centers for Disease Control and Prevention, Atlanta, GA, USA, and Dr. Jonny Yokosawa, Guest Researcher at Universidade Federal de Uberlândia, MG, Brazil, for useful discussions and help with this study. We also thank Dr. Saulo Duarte Passos, Universidade de São Paulo, São Paulo, SP, Brazil, for some specimen collections, and the student nurses for visiting the patients.

\section{References}

1. Anderson LJ \& Heilman CA (1995). Protective and disease-enhancing immune responses to respiratory syncytial virus. J oumal of Infectious Diseases, 171: 1-7.

2. Kimpen J LL (1996). Respiratory syncytial virus immunology. Pediatric Allergy and Immunology, 7 (Suppl 9): 86-90.

3. Watt PJ , Zardis M \& Lambden PR (1986). Age related IgG subclass response to respiratory syncytial virus fusion protein in infected infants. Clinical and Experimental Immunology, 64: 503-509.

4. Forster J, Streckert HJ \& Werchau H (1995). The humoral immune response of children and infants to an RSV infection: its maturation and association with illness. Klinische Pädiatrie, 207: 313-316.

5. Cox MJ , Azevedo RS, Cane PA, Massad E \& Medley GF (1998). Seroepidemiological study of respiratory syncytial virus in São Paulo State, Brazil. J oumal of Medical Virology, 55: 234-239.

6. Anderson LJ , Tsou C, Potter C, Keyserling HL, Smith TF, Ananaba G \& Bangham CR (1994). Cytokine response to respiratory syncytial virus stimulation of human penipheral blood mononuclear cells. J ournal of Infectious Diseases, 170: 1201-1208.

7. Rabatic S, Gagro A, Lokar-Kolbas R, Krsulovic-Hresic V, Vrtar Z, Popow-Kraupp $\mathrm{T}$, Drazenovic $\vee \&$ M Minaric-Galinovic G (1997). Increase in CD23+ B cells in infants with bronchiolitis is accompanied by appearance of IgE and IgG4 antibodies specific for respiratory syncytial virus. J oumal of Infectious Diseases, 175: 32-37.

8. Raes $M$, Peeters $V$, Alliet $P$, Gillis $P$, Kortleven J , Magerman K \& Rummens J L (1997). Peripheral blood T and B lymphocyte subpopulations in infants with acute respiratory syncytial virus bronchiolitis. Pediatric Allergy and Immunology, 8: 97102.

9. Lamprecht $\mathrm{CL}$, Krause $\mathrm{HE} \&$ Mufson $\mathrm{MA}$ (1976). Role of matemal antibody in pneumonia and bronchiolitis due to respiratory syncytial virus. J ournal of Infectious Diseases, 134: 211-217.

10. Glezen WP, Paredes A, Allison J E, Taber LH \& Frank AL (1981). Risk of respiratory syncytial virus infection for infants from low-income families in relationship to age, sex, ethnic group, and maternal antibody level. J oumal of Pediatrics, 98: 708-715.

11. Prince GA, Horswood RL \& Chanock RM (1985). Quantitative aspects of passive immunity to respiratory syncytial virus infection in infant cotton rats. J ournal of Virology, 55: 517-520.

12. Walsh $\mathrm{EE}$, Hall $\mathrm{CB}$, Briselli $\mathrm{M}$, Brandriss MW \& Schlesinger JJ (1987). Immunization with glycoprotein subunits of respiratory syncytial virus to protect cotton rats against viral infection. J oumal of Infectious Diseases, 155: 1198-1204.

13. Tang YW \& Graham BS (1997). T cell source of type 1 cytokines determines illness patterns in respiratory syncytial virus-infected mice. J ournal of Clinical Investigation, 99: 2183-2191.

14. Openshaw PJ M (1995). Immunity and immunopathology to respiratory syncytial virus - The mouse model. American J ournal of Respiratory and Critical Care Medicine, 152: S59-S62.

15. Welliver RC (1998). Respiratory syncytial virus immunoglobulin and monoclonal antibodies in the prevention and treatment of respiratory syncytial virus infection. Seminars in Perinatology, 22: 87-95.

16. Chandwani S, Borkowsky W, Krasinski K Lawrence R \& Welliver R (1990). Respiratory syncytial virus infection in human immunodeficiency virus-infected children. J oumal of Pediatrics, 117 (Part 1): 251254.

17. King J r J C, Burke AR, Clemens J D, Nair P, Farley J J , Vink PE, Batlas SR, Rao M \& J ohnson J P (1993). Respiratory syncytial virus illnesses in human immunodeficiency virus- and noninfected children. Pediatric Infectious Disease J oumal, 12: 733739.

18. Brandenburg AH, Groen J, van SteenselMoll HA, Claas EC, Rothbarth PH, Neijens HJ \& Osterhaus ADME (1997). Respiratory syncytial virus specific senum antibodies in infants under six months of age: limited serological response upon infec- 
tion. J oumal of Medical Virology, 52: 97104.

19. Murphy BR, Graham BS, Prince GA, Walsh EE, Chanock RM, Karzon DT \& Wright PF (1986). Serum and nasal-wash immunoglobulin $G$ and $A$ antibody response of infants and children to respiratory syncytial virus $\mathrm{F}$ and $\mathrm{G}$ glycoproteins following primary infection. Journal of Clinical Microbiology, 23: 1009-1014.

20. Vainionpaa $\mathrm{R}$, Meurman $\mathrm{O} \&$ Sarkkinen $\mathrm{H}$ (1985). Antibody response to respiratory syncytial virus structural proteins in children with acute respiratory syncytial virus infection. J ournal of Virology, 53: 976-979.

21. Mclntosh K \& Fishaut J M (1980). Immunopathologic mechanisms in lower respiratory tract disease of infants due to respiratory syncytial virus. Progress in Medical Virology, 26: 94-118.

22. Hornsleth $A$, Bech-Thomsen $N \&$ Friis $B$ (1985). Detection by ELISA of IgG-subclass-specific antibodies in primary respiratory syncytial (RS) virus infections. J ournal of Medical Virology, 16: 321-328.

23. J ankowski M, Homsleth A \& Olsen PG (1990). IgG-subclass-specific antibody reactivity to respiratory syncytial virus polypeptides investigated by Western blot. Research in Virology, 141: 343-353.

24. Wilczynski J, Lukasik B, Torbicka E, Tranda I \& Brzozowska-Binda A (1994). The immune response of small children by antibodies of different classes to respiratory syncytial virus (RSV) proteins. Acta Microbiologica Polonica, 43: 369-379.

25. Waris ME, Tsou C, Erdman DD, Day DB \& Anderson LJ (1997). Priming with live respiratory syncytial virus (RSV) prevents the enhanced pulmonary inflammatory response seen after RSV challenge in BALB/c mice immunized with formalininactivated RSV. J ournal of Virology, 71: 6935-6939.

26. Brandenburg AH, Kleinjan A, van Het Land B, Moll HA, Timmerman HH, de Swart RL, Neijens HJ , Fokkens W \& Osterhaus AD (2000). Type 1-like immune response is found in children with respiratory syncytial virus infection regardless of clinical severity. J oumal of Medical Virology, 62: 267-277.

27. Graham BS (1995). Pathogenesis of respiratory syncytial virus vaccine-augmented pathology. American J oumal of Respiratory and Critical Care Medicine, 152: S63S66.

28. Waris ME, Tsou C, Erdman DD, Zaki SR \& Anderson LJ (1996). Respiratory syncytial virus infection in BALB/C mice previously immunized with formalin-inactivated virus induces enhanced pulmonary inflammatory response with a predominant Th2like cytokine pattern. J ournal of Virology, 70: 2852-2860.

29. Roman M, Calhoun WJ, Hinton KL, Avendano LF, Simon V, Escobar AM, Gaggero A \& Diaz PV (1997). Respiratory syncytial virus infection in infants is associated with predominant Th-2-like response. American J ournal of Respiratory and Critical Care Medicine, 156: 190-195.

30. Arruda E, Crump CE, Rollins BS, Ohlin A \& Hayden FG (1996). Comparative susceptibilities of human embryonic fibroblasts and HeLa cells for isolation of human rhinoviruses. J oumal of Clinical Microbiology, 34: 1277-1279.

31. Carpenter AB (1997). Enzyme-linked immunoassays. In: Rose NR, Conway de Macario E, Folds JD, Lane HC \& Nakamura RM (Editors), Manual of Clinical Laboratory Immunology. 5th edn. American Society for Microbiology, Washington, DC, USA, 25-26.

32. Staros JV, Wright RW \& Swingle DM (1986). Enhancement by N-hydroxysulfosuccinimide of water-soluble carbodiimide-mediated coupling reactions. AnaIytical Biochemistry, 156: 220-222.

33. Hamilton RG (1987). Human IgG subclass measurements in the clinical laboratory. Clinical Chemistry, 33: 1707-1725.

34. Wilczynski J \& Lukasik B (1994). Transplacental transfer of antibodies to some respiratory viruses. Acta Microbiologica Polonica, 43: 347-358.

35. Glezen WP \& Alpers M (1999). Maternal immunization. Clinical Infectious Diseases, 28: 219-224.
36. Colocho Zelaya EA, Pettersson CA, Forsgren M, Orvell C \& Strannegard O (1994). Respiratory syncytial virus infection in hospitalized patients and healthy children in El Salvador. American J ournal of Tropical Medicine and Hygiene, 51: 577-584.

37. Meuman O, Waris M \& Hedman K (1992). Immunoglobulin $\mathrm{G}$ antibody avidity in patients with respiratory syncytial virus infection. J oumal of Clinical Microbiology, 30: 1479-1484.

38. Tsutsumi H, Matsuda K, Yamazaki H, Ogra PL \& Chiba S (1995). Different kinetics of antibody responses between IgA and IgG classes in nasopharyngeal secretion in infants and children during primary respiratory syncytial virus infection. Acta Paediatrica J aponica, 37: 464-468.

39. Comans-Bitter $W M$, de Groot $R$, van den Beemd R, Neijens HJ, Hop WC, Groeneveld $\mathrm{K}$, Hooijkaas $\mathrm{H} \&$ \& van Dongen J J (1997). Immunophenotyping of blood lymphocytes in childhood. Reference values for lymphocyte subpopulations. J ournal of Pediatrics, 130: 388-393.

40. Durandy A, De Saint Basile G, LisowskaGrospierre B, Gauchat J F, Forveille M, Kroczek RA, Bonnefoy JY \& Fischer A (1995). Undetectable CD40 ligand expression on $\mathrm{T}$ cells and low $\mathrm{B}$ cell responses to CD40 binding agonists in human newborns. J oumal of Immunology, 154: 15601568.

41. McCloskey TW, Cavaliere T, Bakshi S, Harper R, Fagin J, Kohn N \& Pahwa S (1997). Immunophenotyping of T lymphocytes by three-color flow cytometry in healthy newboms, children, and adults. Clinical Immunology and Immunopathology, 84: 46-55.

42. Salkind AR, Nichols JE \& Roberts J r NJ (1991). Suppressed expression of ICAM1 and LFA-1 and abrogation of leukocyte collaboration after exposure of human mononuclear leukocytes to respiratory syncytial virus in vitro. Comparison with exposure to influenza virus. J ournal of Clinical Investigation, 88: 505-511. 